\title{
Mechanical evaluation of timber conservation processes by bending tests
}

\author{
Dulce Franco Henriques $^{1, a}$, Lina Nunes ${ }^{2,4 b}$ and Jorge de Brito ${ }^{3, c}$ \\ ${ }^{1}$ Department of Civil Engineering - Instituto Superior de Engenharia de Lisboa - ISEL, Lisbon, \\ Portugal \\ ${ }^{2}$ Structures Department, Laboratório Nacional de Engenharia Civil, Lisbon, Portugal \\ ${ }^{3}$ Department of Civil Engineering and Architecture, Instituto Superior Técnico, Technical University \\ of Lisbon, Portugal \\ ${ }^{4}$ Azorean Biodiversity Group (CITA-A) and Platform for Enhancing Ecological Research \& \\ Sustainability (PEERS), Universidade dos Açores, 9700-042 Angra do Heroísmo, Terceira, Açores \\ a mfhenriques@dec.isel.pt, ${ }^{\mathrm{b}}$ linanunes@Inec.pt, ${ }^{\mathrm{c}} \mathrm{jb} @$ civil.ist.utl.pt
}

Keywords: Wood, degradation, conservation, consolidation, old buildings.

\begin{abstract}
This paper presents the laboratory work performed with the purpose of understanding the mechanical performance of $340 \times 20 \times 20 \mathrm{~mm}$ maritime pine wood samples degraded by rot fungi when treated with a biocide product followed by consolidation through impregnation with a polymeric product.

Four commercially available products were used: a water-based biocide, BC, a solvent-based biocide, X, an acrylic consolidant, PB (PB 72), and an epoxy-based consolidant, E.

Seven sets of specimens each one having a varied range of fungal degradation were prepared. Then the product combinations were applied by brush to six sets of specimens (E, X-E, BC-E, PB, X-PB, $\mathrm{BC}-\mathrm{PB}$ ) of which one was left untreated for control, 0-0. Finally all sets were subjected to static bending strength test until rupture.

Results showed that the acrylic and epoxy-based products lead to increased mechanical capacity of the consolidated wood up to $100 \%$ in some cases in specimens with $70 \%$ of MOE loss. The results presented the same order of magnitude for both wood consolidants. The previous application of biocide did not have a significant impact in the behavioral pattern of the consolidant: a marked improvement of the bending strength of the degraded specimens after treatment and consolidation. These results demonstrated the feasibility of combining biocide/consolidation products, and provide indications of interest to the application of this technique to extend the lifespan of wood elements moderately degraded by fungi in old buildings.
\end{abstract}

\section{Introduction}

The option of removing building timber elements when they have a moderate level of deterioration by fungi is considered not acceptable. Solutions that preserve the physical and mechanical integrity of constructions are needed, and more so when the building has historical value.

Wood is a natural biodegradable product. Nevertheless humans have always tried to prevent wood decay and destruction by climate, pests and fire [1]. In fact, once wood is in service and protected it can last centuries, as long as the protective conditions remain stable [2-4]. Even if the timber lies slightly deteriorated the option of keeping the original elements in the building has been gaining importance, because removing them detracts from the building's historical identity. Extensive replacement of elements is both expensive and often also unnecessary; it may change the characteristics of the structure, and it disrupts the normal use of the building [5]. Furthermore, the sustainable use of forest resources means that timber must be used more efficiently and its life in service increased, hence a greater use of protection technologies [6]. 
In such cases, it is convenient to use a biocide to stop fungal activity and then consolidate the degraded elements so that the timber keeps on fulfilling its structural and decorative functions. In 1986, Nakhla recommended that a fungicide should be applied whenever the use of synthetic resins was required in wooden works of art [7], and application of biocides became a routine practice in the conservation of art works [8], even though studies about compatibility of different products are scarce.

In situations where it is as important to apply a wood preservative and a consolidant, it is necessary to know their combined performance [9]. This conservation approach seems to be applicable to degraded wooden elements up to around $20 \%$ mass loss or $70 \%$ MOE loss [9].

\section{Laboratory tests}

Materials and methods. Specimen preparation was divided in two phases: cutting and selection, and fungal degradation of wood in laboratory conditions. Two biocide treatments were then applied, followed by two consolidation products, identified as follows:

- Treatment products $\quad$ - X (Xylophene SOR $40^{\circledR}$ - Dyrup);

- BC (Bora-care ${ }^{\circledR}$ - Nisus Corporation).

- Consolidation products - E (EPO 155® + K $156^{\circledR}$ - C.T.S. Srl.);

- PB (Paraloid B72 ${ }^{\circledR}$ - Rohm and Haas).

Products are applied in each group of nine specimens and mechanical tests of static bending strength were then conducted as presented in Fig. 1. Results are interpreted through comparison with the control group (0-0).

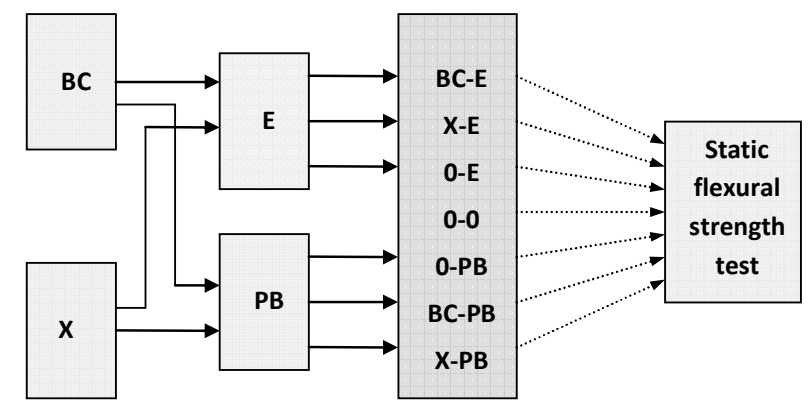

Fig 1 - Schematic representation of products application and mechanical test

Specimens. Maritime pine (Pinus pinaster Ait.) dry wood was cut into the size $20 \times 20 \times 340$ $\mathrm{mm}$. The wood was taken from different trees, and specimens were grouped by ten unities. The selection of specimens for testing was in accordance with the physical characteristics specified in European Standard EN113 [10]: exclusively sapwood, free from defects, maximum dimensional deviation of $0.5 \mathrm{~mm}$ in any of the dimensions, annual growth rings between 2.5 and 8 per $10 \mathrm{~mm}$, proportion of late wood in the annual rings not exceeding $30 \%$ of the whole.

The specimens size was established according to the standard Norma Portuguesa NP619 [11], since these specimens were to undergo the static.

Wood degradation. Degradation of the specimens was achieved by exposing them to a natural environment (a calibrated vegetable soil mixture) in boxes with ventilated lids. The mixture was prepared according to British Standard BS15083-2 [12] and the degradation process was run for 6 to 9 months in a conditioned room at $25 \pm 2{ }^{\circ} \mathrm{C}$ temperature and $80 \pm 5 \% \mathrm{RH}$.

The test specimens were placed inside the boxes such that the outer $50 \mathrm{~mm}$ of the specimens were not in direct contact with the moistened soil (Figs. 2.b) and 4.b)). The degradation level was assessed by the modulus of elasticity (MOE) loss. The MOE parallel to the fibres was measured at intervals of three months during the degradation process. This method resulted from the adaptation of two standards $[11,12]$ 

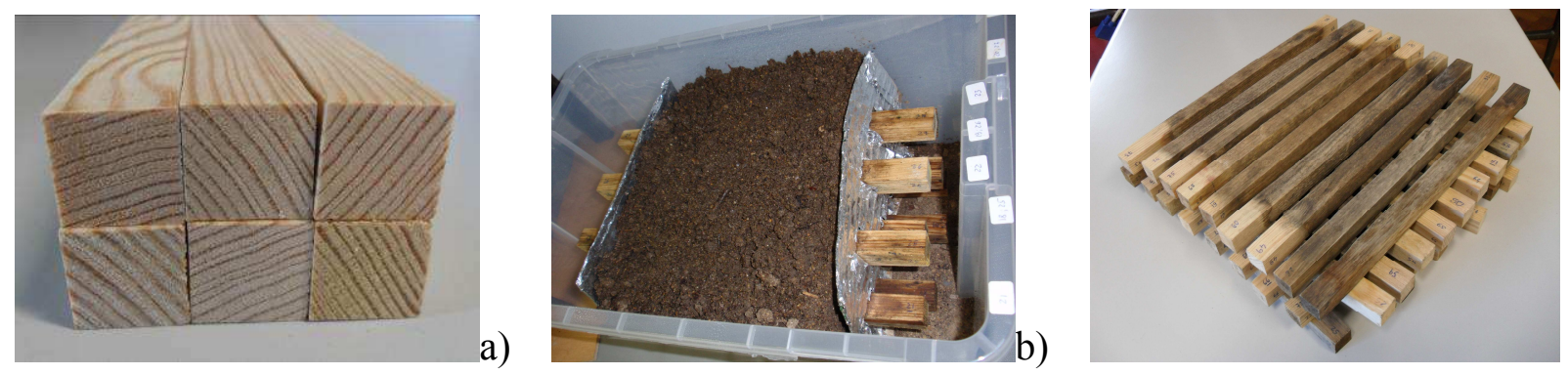

c)

Fig 2 - Preparing wood specimens: a) Selection; b) Process of degradation; c) Look of degraded samples

Treatment products. A boron-based product, BC, was selected because of its characteristics: very low toxicity to mammals, good fungicidal and insecticidal capability, increment to timber fire resistance, low cost, and easy to manipulate [13] [14]. Provided with $40 \%$ concentration of DOT (tetra-hydrated octoborate dissodium) it had to be diluted in water before use. Since the purpose was to simulate a current situation in structural elements of buildings the option was to use the dilution recommended by the manufacturer for timber degraded by fungi with a thickness equal or higher than $50 \mathrm{~mm}$ : ratio 1:1 by volume. Product $\mathrm{X}$ was selected because of this ample biocidal spectrum (insecticide and fungicide), this ease of application (directly with no dissolution) and this easy to purchase in Portugal (for current commercial surfaces). Table 1 provides the characteristics of the two products (percentages by mass).

The impregnation depth achieved by such a solution applied to timber from an old building previously treated with an unknown product was previously studied by the same authors, having led to satisfactory results [15].

Table 1: Treatment products' characteristics

\begin{tabular}{|c|c|lr|c|}
\hline Product & Type & \multicolumn{1}{|c|}{ Active ingredients (a.i.) } & Solvent \\
\hline \multirow{4}{*}{$\mathbf{X}$} & \multirow{3}{*}{ LOSP } & Cypermethrin & $0.07 \%$ & \\
& & Propiconazole & $0.15 \%$ & White \\
& & Tebuconazole & $0.05 \%$ & spirit \\
& & IPBC - iodo-2-propynyl-butylcarbamate & $0.05 \%$ & \\
\hline \multirow{2}{*}{ BC } & Aqueous & DOT - tetra-hydrated octoborate & $23.00 \%$ & \multirow{2}{*}{ Water } \\
& solution & dissodium & & \\
\hline
\end{tabular}

Consolidants. These products were selected for the following characteristics: penetration capacity in the wood, mechanical strength, durability, hardening without shrinkage, easy of application, low toxicity, good aesthetics, low price and ease of acquisition [7, 16, 17]. Two commercial consolidants were used (E and $\mathrm{PB}$ ), after selection tests performed by the same authors [18].

Consolidant $\mathrm{E}$ is a thermo-hardening epoxy-based product. The resin component is based on diglycidyl ether of bisphenol A (DGEBA) and the hardener is made of aliphatic and cycloaliphatic amines. A pot life of $40 \mathrm{~min}$ at $22^{\circ} \mathrm{C}$ was obtained.

Consolidant PB is a thermoplastic acrylic-related product currently used as an adhesive and consolidant for works of art with wood components: Paraloid B72 [17]. Since the penetration capacity of the resin strongly depends on the solvent and on its proportion in the composition [7, 19], several preliminary selection tests were performed [18]. Acetone was chosen as solvent at a mass ratio of $80 / 20$ (acetone/PB). A pot life of $50 \mathrm{~min}$ at $22^{\circ} \mathrm{C}$ was obtained.

All products were applied with a brush until wood surface saturation was reached [20], in order to simulate the application of the product to wood in service. 
Mechanical tests The static bending test with three load points was carried out by applying a progressively greater force at a constant rhythm, until specimen failure, after about three minutes [11] (Fig. 3 and 4(c)).

Six degraded specimens and three non-degraded specimens were tested for each mechanical test and combination of products. Furthermore, a similar set of non-consolidated and non-treated control specimens were submitted to each of the mechanical tests.

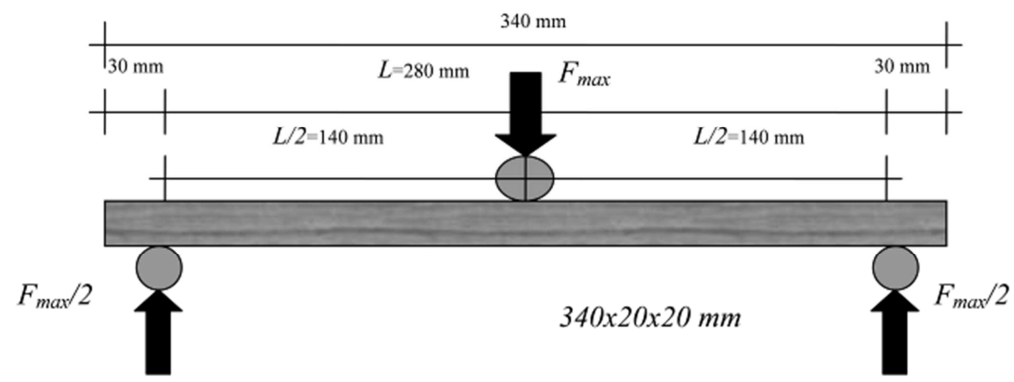

Fig 3 - Schematic presentation of static bending test
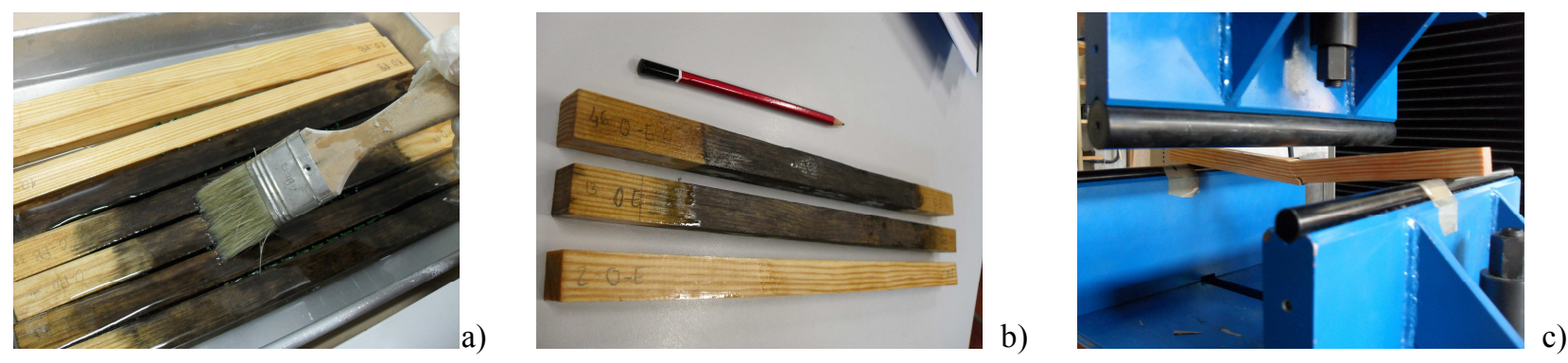

Fig 4 - a) Product application; b) Treated and consolidated specimens; c) Static bending test

\section{Results and discussion}

Retention of consolidant in treated timber. Fig. 5.a),b) and Fig. 6.a),b) show scatter diagrams, each of which refers the values relative to the consolidation in untreated timber and timber treated with one of the products.

The determination of the levels of retention of consolidant was made using the values of the mass stabilized at $12 \%$ of each specimen, before and after the application of the product, and of the are exposed to soaking (central part of the specimen) according to Eq. 1:

$$
R_{(c)}=\frac{m_{(c), 12 \%}-m_{12 \%}}{A_{\exp }}\left(\mathrm{kg} / \mathrm{m}^{2}\right) .
$$

Where: $\mathrm{R}_{(\mathrm{c})}$ - mass of consolidant retained by $\mathrm{m}^{2}$;

$m_{12 \%}$ - mass of the specimens at $12 \%$ water content, before consolidation, in $\mathrm{kg}$;

$m_{\text {(c) }), 12 \%}$ - mass of the consolidated specimens, stabilized at $12 \%$ of water content, in $\mathrm{kg}$;

$A_{\text {exp }}$ - area of the specimen exposed to soaking, in $\mathrm{m}^{2}$.

By analysing the relative location of the clouds of values corresponding to the consolidant $\mathrm{E}$ in untreated timber and treated timber, it is found that there is a clear change on what concerns their retention capacity before and after the treatment, for the pair X-E. As for the pair BC-E, the consolidant retention values are generally lower than those measured in untreated timber.

As for the pairs of PB consolidant with the biocide products under analysis (Fig. $6 \mathrm{a}, \mathrm{b}$ ), there were distinct situations according to the pairs under analysis. The treatment products slightly reduce the consolidation effect, except for the pair $\mathrm{X}-\mathrm{PB}$, in which there is hardly any change in mechanical strength, relative to $0-\mathrm{PB}$. 

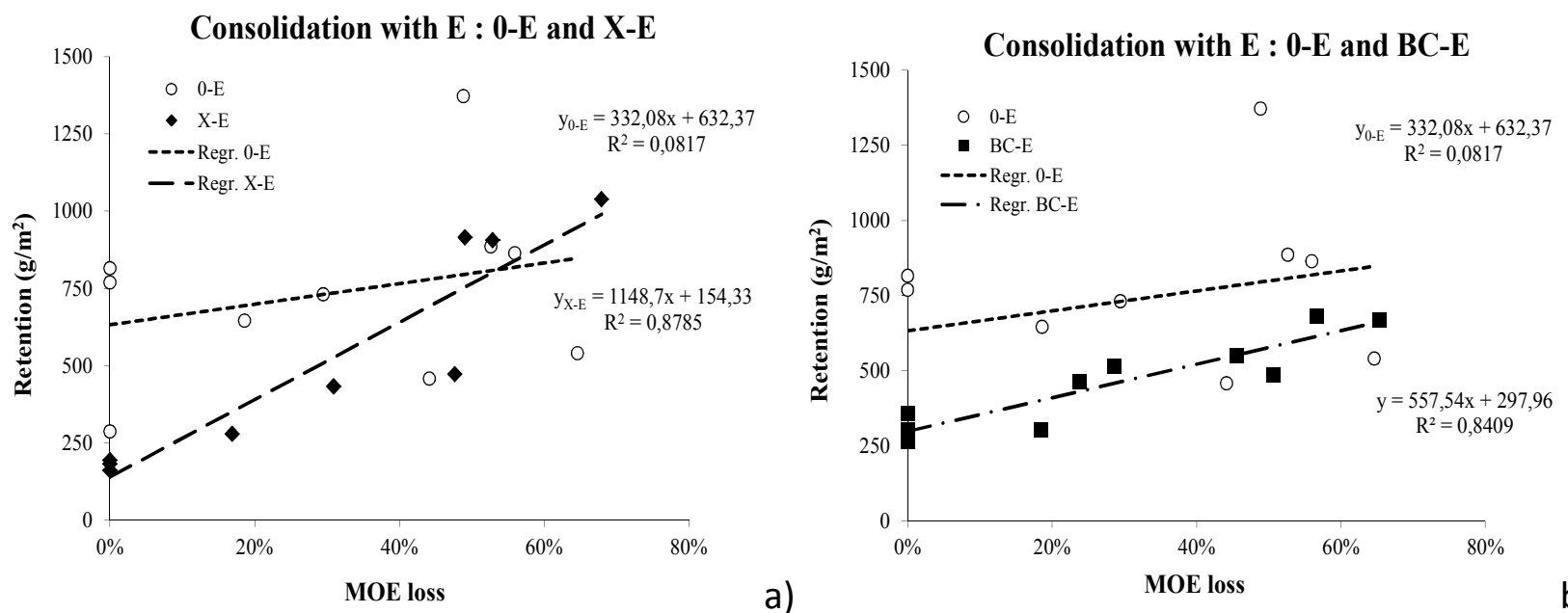

b)

Fig 5 - Retention of consolidant E: a) in wood not treated (0-E) and in wood treated with X (X-E); b) $\mathrm{PB}$ in wood not treated $(0-\mathrm{E})$ and in wood treated with $\mathrm{BC}(\mathrm{BC}-\mathrm{E})$
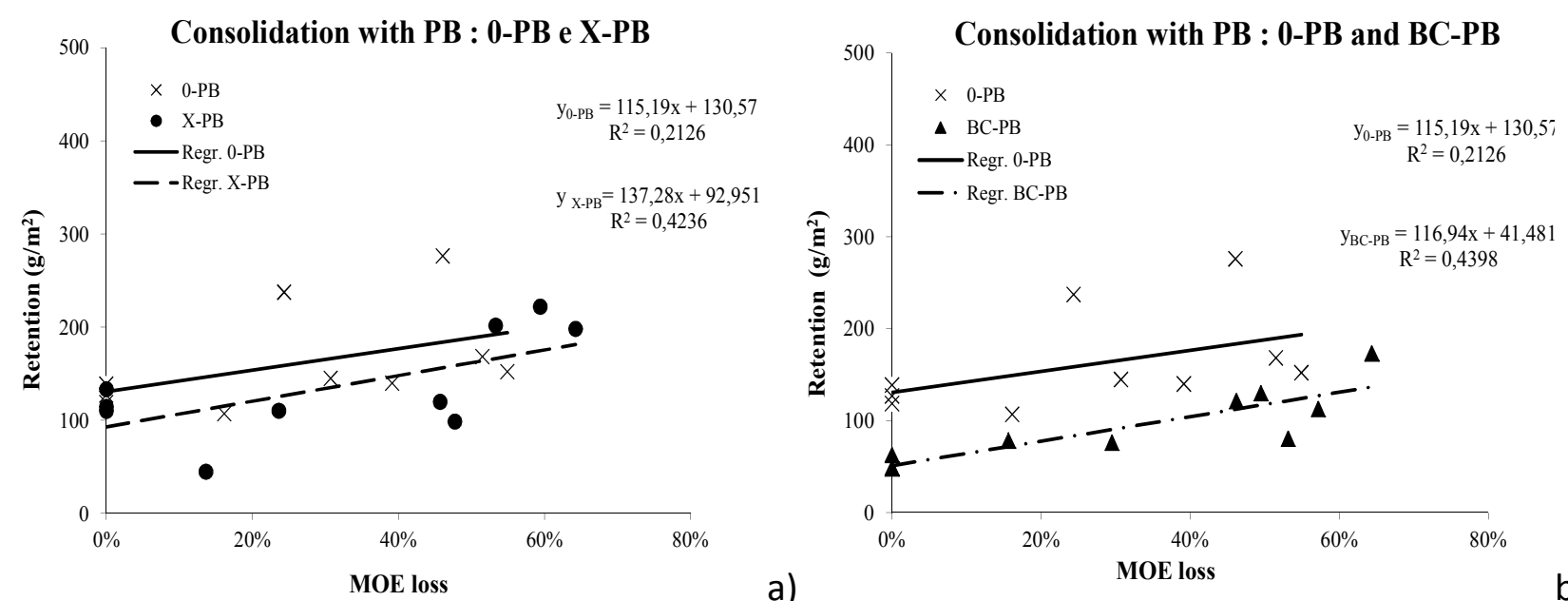

Fig 6 - Retention of consolidant PB: a) in wood not treated (0-PB) and in wood treated with $\mathrm{X}$ $(\mathrm{X}-\mathrm{PB}) ; \mathrm{b})$ in wood not treated (0-PB) and in wood treated with $\mathrm{BC}(\mathrm{BC}-\mathrm{PB})$

Knowing that the amounts of PB consolidant retained in untreated timber are roughly in the range of $100-300 \mathrm{~g} / \mathrm{m}^{2}$, there is a decrease of the amounts retained in all the pairs to values around $50-230 \mathrm{~g} / \mathrm{m}^{2}$.

Relatively to consolidant E, there are much higher retention levels, in the $300-14001400 \mathrm{~g} / \mathrm{m}^{2}$ range for untreated timber and $150-11001400 \mathrm{~g} / \mathrm{m}^{2}$ for treated timber.

Bending Strength. The bending strength of each tested specimen was calculated according to Eq. 2, as follows:

$$
f_{m, 12 \%}=\frac{3 F_{\max } L}{2 b h^{2}} \quad\left(\mathrm{~N} / \mathrm{mm}^{2}\right) .
$$

Where: $\mathrm{f}_{\mathrm{m}, 12 \%}$ - bending strength to a $12 \%$ of moisture, $\mathrm{N} / \mathrm{mm}^{2}$;

$\mathrm{F}_{\max }-$ maximum force of rupture, $\mathrm{N}$;

$\mathrm{L}$ - span between supports, $\mathrm{mm}$;

$\mathrm{b}$ and $\mathrm{h}$ - section dimensions, $\mathrm{mm}$;

Each specimen provided a pair of values $\left(M l, f_{m}\right): M l$ (MOE loss) and $f_{m}$ (bending strength). Graphs were prepared for each treatment and consolidation pair and a regression line was calculated (Fig. 7). 
The numerical interpretation of the graphs in Fig. 7 is presented in Table 2 as the percentiles of strength increment prompted by each consolidant or treatment + consolidant $(t+c)$ in relation to the control specimen (0-0), determined according to Eq. 3, whose ordinate $f_{m}$ is obtained from the respective exponential regression lines presented in Table 2, as a function of $M l$.

$$
I_{(t+c), M l}=\frac{f_{m(t+c), M l}-f_{m(0), M l}}{f_{m(0), M l}} .100(\%) .
$$

Where: $\mathrm{I}_{(t+c), M l}$ - percentile increment promoted by products $t+c$ in relation to the control;

$f_{m(t+c), M l}$ - ordinate of the regression line of products $t+c$;

$f_{m(0), M l}$ - ordinate of the control regression line.

Treatment and consolidation with $\mathbf{E}$

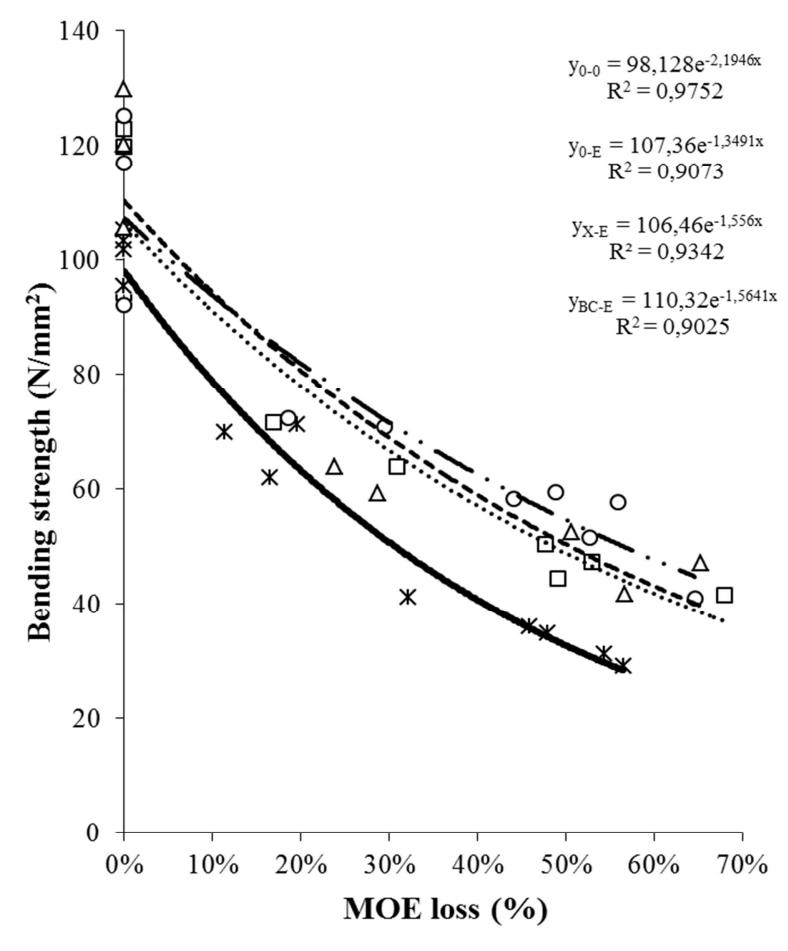

* $0-0$

○ 0 -E

$\triangle$ BC-E

$\square \quad \mathrm{X}-\mathrm{E}$

Corr 0-0

- C Corr 0-E

---Corr BC-E

Corr X-E

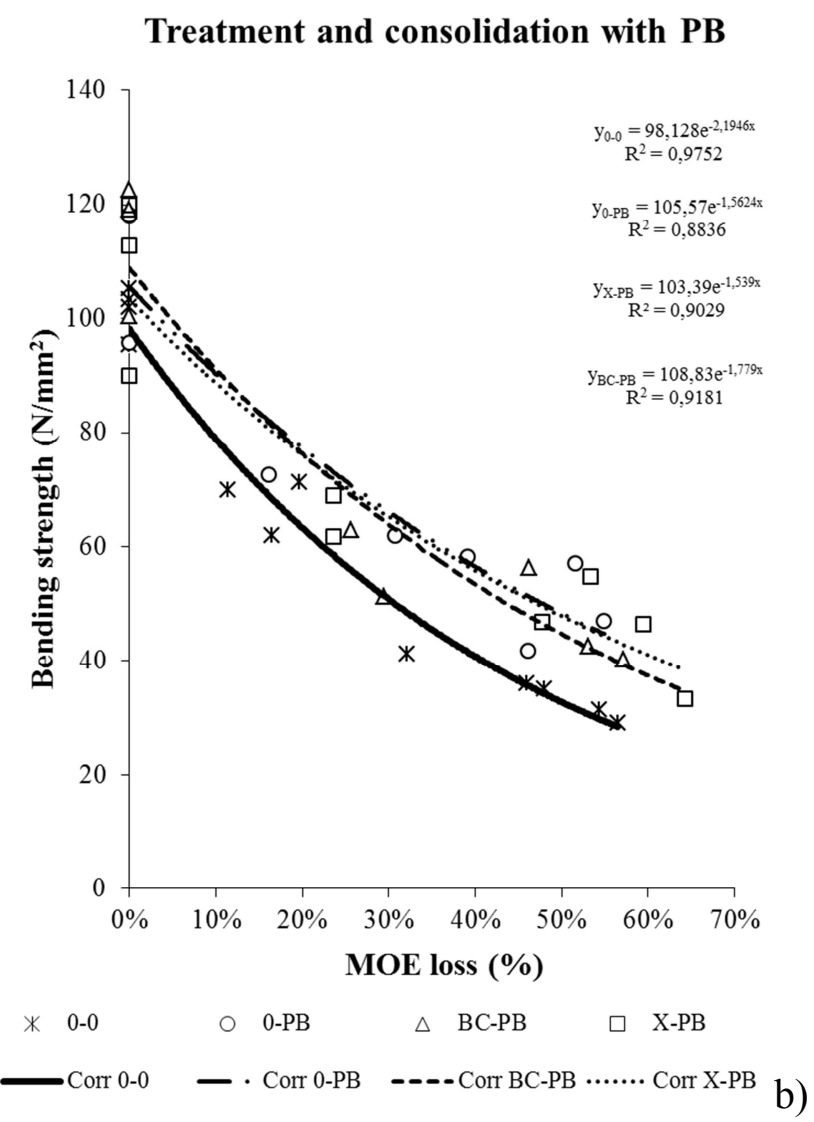

Fig. 7: Bending strength versus MOE loss: a) control, consolidation with E and pairs treatment/consolidation with E; b) control, consolidation with $\mathrm{PB}$ and pairs treatment/consolidation with PB

Table 2: Bending strength

\begin{tabular}{|c|c|c|c|c|c|c|c|c|c|c|c|c|c|c|c|c|c|c|c|c|c|}
\hline \multirow[b]{2}{*}{ MOE loss (\%) } & \multicolumn{3}{|c|}{$0-0$} & \multicolumn{3}{|c|}{$0-E$} & \multicolumn{3}{|c|}{ X-E } & \multicolumn{3}{|c|}{ BC-E } & \multicolumn{3}{|c|}{ 0-PB } & \multicolumn{3}{|c|}{ X-PB } & \multicolumn{3}{|c|}{ BC-PB } \\
\hline & 0 & 35 & 70 & 0 & 35 & 70 & 0 & 35 & 70 & 0 & 35 & 70 & 0 & 35 & 70 & 0 & 35 & 70 & 0 & 35 & 70 \\
\hline $\begin{array}{l}\text { Strength } \\
\left(\mathrm{N} / \mathbf{m m}^{2}\right)\end{array}$ & 98 & 46 & 21 & 107 & 67 & 42 & 107 & 62 & 36 & 110 & 64 & 38 & 106 & 61 & 35 & 103 & 60 & 35 & 109 & 58 & 31 \\
\hline Increment (\%) & - & - & - & 9 & 47 & 98 & 9 & 36 & 70 & 12 & 41 & 78 & 8 & 34 & 68 & 5 & 33 & 67 & 11 & 28 & 48 \\
\hline $\mathrm{R}^{2}$ & & 0.98 & & & 0.91 & & & 0.93 & & & 0,9 & & & 0.88 & & & 0,9 & & & 0.92 & \\
\hline
\end{tabular}


The low dispersion of the mechanical results, expressed by $\mathrm{R}^{2}$ values very close to one, confirms a high degree of confidence in the results obtained.

The bending test showed a marked improvement of the strength of the degraded specimens after treatment and consolidation, though this was only applied superficially by brushing.

Degraded timber shows great loss in bending strength relative to sound wood.

However focusing analysis in strength increment prompted by each consolidant in relation to the control specimen (Eq. 5 and Tab. 2) it appears that consolidants promote significant increases in bending strength for both cases. These are in the order of $30-50 \%$ to $35 \%$ of MOE loss and $70-100 \%$ for $70 \%$ of MOE loss. Exception to the combination of BC-PB which shows lower values.

\section{Conclusions}

The application of the acrylic and epoxy-based consolidants may increase the mechanical resistance of consolidated wood. Although low levels of degradation may be remedied by the use of consolidants, the original mechanical condition of sound wood is never recovered.

The mechanical results are of the same order of magnitude for both consolidants, acrylic and epoxy, only slightly better with the latter, although the retention levels of PB inside the timber being substantially below of those with E.

The application of treatment products before consolidation decreases the latter's effect but not a great extent for most of the products combinations [9]. However for the pair X-PB there is no decrease of strength.

The pair of products (treatment/consolidant) which showed the best results was BC-E, according to the tests performed, increased wood resistance was observed after the application of these products.

\section{Acknowledgements}

The authors would like to thank the Fundação para a Ciência e Tecnologia (FCT) for the project CONSERV-TIMBER (ref. EXPL/ECM-COM/0664/2012) and Dr. Jeff Lloyd from Nisus Corporation for supplying treatment products. The authors also wish to acknowledge the support of the research centre ICIST (Instituto de Engenharia de Estruturas, Território e Construção), IST, Technical University of Lisbon and of the National Laboratory of Civil Engineering (LNEC).

\section{References}

[1] A. Unger, W. Unger, Conservation of wooden cultural property, Proceedings of The International Research Group on Wood Preservation, IRG/WP 94-30038, Bali, Indonesia, 1994.

[2] T. Highley, Biodeterioration of wood, Wood handbook - Wood as an engineering material, Gen. Tech. Rep. FPL-GTR-113, Department of Agriculture, Forest Service, Forest Products Laboratory, Madison, U.S.A., 1999.

[3] R.W. Berry, Remedial treatment of wood rot and insect attack in buildings, Building Research Establishment, Garston, Watford, 1994.

[4] K.E. Larsen, N. Marstein, Conservation of historic timber structures - An ecological approach. Butterworth-Heinemann Edit., Reed Elsevier plc group, United Kingdom, 2000.

[5] P. Lavisci, S. Beri, B. Pizzo, P. Triboulot, R. Zanuttini, A shear test for structural adhesives used in the consolidation of old timber, Holz als Roh - Werkstoff 59 (2001) 145-152.

[6] A.F. Preston, Wood preservation - Trends of today that will influence the industry tomorrow, Forest Products Journal, 50(9) (2000) 12-19.

[7] S.M. Nakhla, A comparative study of resins for the consolidation of wooden objects, Studies in Conservation, 31 (1986), 38-44. 
[8] J.-D. Gu, Microbiological deterioration and degradation of synthetic polymeric materials: recent research advances, International Biodeterioration \& Biodegradation, 52 (2003) 69-91.

[9] D. Henriques, et al., Consolidating preservative-treated wood: Combined mechanical performance of boron and polymeric products in wood degraded by Coniophora puteana, Journal of Cultural Heritage (2013), in press, http://dx.doi.org/10.1016/j.culher.2012.11.008.

[10]European Standard EN113 Wood preservatives - Test method for determining the protective effectiveness against wood destroying basidiomycetes - Determination of the toxic values, European Committee for Standardization, Brussels, 1980.

[11] Norma Portuguesa NP619 Static bending test (in Portuguese). IGPAI, Lisbon, Portugal, 1973.

[12]British Standard BS 15083-2, Durability of wood and wood-based products - Determination of the natural durability of solid wood against wood-destroying fungi, test methods - Part 2: Soft rotting micro-fungi. British standards, United Kingdom, 2005.

[13] C.R. Coggins, Trends in timber preservation - A global perspective, Journal of Tropical Science, 20(4), (2008), pp. 264-272.

[14] F.C. Jorge, L. Nunes, C. Botelho, Boron in wood preservation: problems, challenges and proposed solutions. An overview on recent research. Journal of the Faculty Science Technology, University Fernando Pessoa 1 (2004) 3-15.

[15]D.F. Henriques, L. Nunes, J. de Brito, Development of a penetration test for timber impregnation products for use in old buildings, Construction and Building Materials 24 (7) (2010) 1095-1100.

[16]M.E. Weaver, Conserving Buildings - A Manual of Techniques and Materials, Preservation press. John Wiley \& Sons, Inc. USA, 1997.

[17] G.M. Crisci, M.F. La Russa, M. Malagodi, S.A. Ruffolo, Consolidating properties of Regalrez 1126 and Paraloid B72 applied to wood, Journal of Cultural Heritage, 11 (2010) 304-308.

[18] D.F. Henriques, L. Nunes, J. de Brito, Consolidation of timber degraded by fungi in buildings: an experimental approach, proceedings of CIB World Congress 2010, University of Salford, The Lowry, 2010.

[19] E. Lehmann, S. Hartmann, P. Wyer, Neutron radiography as visualization and quantification method for conservation measures of wood firmness enhancement, Nuclear Instruments and Methods in Physics Research A 542 (2005) 87-94.

[20] J.M.G. Nero, A.P. Duarte, J.C. Bordado, Principles for understanding timber impregnation, Evaluation of the efficiency of impregnation (in Portuguese), Proceedings of 1st Iberian Congress “Timber in Construction", Minho University, Guimarães, Portugal, 2004, pp. 425-436. 